\title{
Prophylactic Effect of Oral Clonidine and Tramadol in Postoperative Shivering in Lower Abdominal Surgery
}

\section{Ebrahim Alijanpour1, Nadia Banihashem1', Parviz Amri Maleh', Hoda Majd ${ }^{2}$, Mohammad-Ali Ropani ${ }^{1}$}

${ }^{1}$ The Clinical Research Development Unite of Rouhani Hospital, Associate of Anesthesiology Department, Babol University of Medical Science, Babol, Iran

${ }^{2}$ Research Committee, Babol University of Medical Sciences, Babol, Iran

Email: nbanihashem@yahoo.com

How to cite this paper: Alijanpour, E., Banihashem, N., Maleh, P.A., Majd, H. and Ropani, M.-A. (2016) Prophylactic Effect of Oral Clonidine and Tramadol in Postoperative Shivering in Lower Abdominal Surgery. Open Journal of Anesthesiology, 6, 137-147. http://dx.doi.org/10.4236/ojanes.2016.69023

Received: September 1, 2016

Accepted: September 25, 2016

Published: September 28, 2016

Copyright $\odot 2016$ by authors and Scientific Research Publishing Inc. This work is licensed under the Creative Commons Attribution International License (CC BY 4.0).

http://creativecommons.org/licenses/by/4.0/ (c) (i) Open Access

\begin{abstract}
Background and Objectives: Several drugs and methods are used to reduce postoperative shivering, the most common complications occurring after surgery. This study aimed to evaluate the effects of the oral Clonidine and Tramadol premedication in reducing postoperative shivering after spinal anesthesia. Materials and Methods: In this study, patients aged 20 - 60 years, based on the American Society of Anesthesia functional class I (Anesthesiologists grade-1), were included in controlled double-blind clinical trials. Each was a candidate of a hydrocele, varicocele, and inguinal hernia under spinal anesthesia. The patients were assigned to three groups and $1 \mathrm{~h}$ prior to surgery, group A received $0.2 \mathrm{mg}$ of Clonidine, group B received 50 $\mathrm{mg}$ of a Tramadol tablet, and group $\mathrm{C}$ received a placebo. We collected information on the severity of shivering, pain intensity levels (VAS score), duration of analgesia, and the patients' hemodynamic condition at base time of 5, 15, and 30 min and 1,2, 4, and $6 \mathrm{~h}$ postoperatively. Results: The incidence of shivering was significantly lower in the Clonidine group than that in the other groups. Analgesia duration was significantly longer in the Clonidine group than that in the control group. In this study, side effects in different groups were not significantly different from each other. Conclusion: Results of this study showed that the oral administration of Clonidine can be effective in preventing the side effects and shivering after spinal anesthesia.
\end{abstract}

\section{Keywords}

Shivering, Spinal Anesthesia, Clonidine, Tramadol 


\section{Introduction}

Currently, regional anesthesia techniques (spinal) are used in many elective and emergency surgeries due to their higher level of safety [1]. Shivering is a common and unpleasant problem witnessed during surgery, which occurs in $40 \%$ - $70 \%$ of patients under spinal anesthesia [1] [2]. Shivering is a potentially serious complication resulting in increased metabolic rate, increased oxygen consumption (up to $100 \%$ - 600\%), and raised carbon dioxide $\left(\mathrm{CO}_{2}\right)$ production, resulting in increase in cardiac output and respiratory problems. This situation is linked to the increased risk of respiratory heart failure in elderly people or in people with heart disease and respiratory problems [3]. Shivering causes surgical site infection, lactic acidosis, muscle fatigue, increased intraocular pressure, and increased intracranial pressure. It also interferes with heart rate monitoring by pulse oximeters, measuring blood pressure, and monitoring electrocardiogram [4]-[6].

Notably, the incidence rate of shivering in regional anesthesia is not less than that in general anesthesia and the patients' hypothermia continues until the loss of drug effect under block level. This is due to sensory messages from the lower extremities to the nerve centers that are disturbed in regional anesthesia in which temperature regulation is also impaired due to the paralyzed limb muscles. As a result, a warm-up time in regional anesthesia is approximately two times higher than that in general anesthesia [3].

The main mechanism of shivering is still unclear, and there are different hypotheses for postoperative shivering. Causes of shivering include pain, decreased sympathetic activity, uncontrolled spinal reflexes, the release of pyrogenic materials, and adrenal suppression. Thermoregulation disorder due to hypothermia (loss of $0.5^{\circ} \mathrm{C}-1^{\circ} \mathrm{C}$ for central heating) is also accepted as the most common factor [6] [7].

Currently, several innovative drug and non-drug solutions are used to prevent and treat hypothermia and shivering, which is one of the most important non-pharmacological methods used to keep patients warm before and during surgery [3] [7]. In addition, there are several pharmacological methods using drugs like Pethidine [8], Ondansetrone [9], Clonidine [10] Anticholinergics [11], Opioid agonist, Dexamethasone, and Tramadol [12].

The present study aims to compare the effects of oral Clonidine and Tramadol in preventing postoperative shivering after spinal anesthesia.

However, the mechanism of shivering after spinal anesthesia is not completely clear. Shivering occurs as a thermoregulatory response to hypothermia or muscle activity with tonic or clonic patterns, and various frequencies have been noticed. However, shivering after spinal anesthesia reported in patients with a normal temperature suggests that mechanisms other than heat loss with a subsequent decrease in the core temperature contribute to the origin of shivering [13]. These mechanisms may inhibit spinal reflexes, anxiety, sympathetic activity, adrenal suppression, progeny release, and respiratory alkalosis.

\section{Materials and Methods}

After obtaining approval from the ethics committee and gaining written informed con- 
sent, 90 men, aged 20 - 60 years, based on the American Society of Anesthesia functional class I (Anesthesiologists grade-1), were considered as candidates of a hydrocele, varicocele and inguinal hernia after spinal anesthesia and were included in a double-blind clinical trial. Patients with history of epilepsy, addiction, allergies, known hypersensitivity to Clonidine and Tramadol, hypertension, diabetes mellitus, cardiovascular diseases and mental disorder were excluded. All patients who underwent more than $2 \mathrm{~h}$ of surgery and all patients with sensory block higher than T4 were excluded. The patient was randomly allocated into three groups with using a random number table (Figure 1). The use of tablets with the same shape, color and the size in each group in order to blind the One hour before surgery, group A received $0.2 \mathrm{mg}$ of Clonidine, group B received $50 \mathrm{mg}$ of a Tramadol tablet, and group $\mathrm{C}$ received a placebo.

After entrance to the operation room, patients were monitored for all standard procedures including an electrocardiography (ECG), non-invasive blood pressure (NIBP), heart rate, and oxygen saturation. The patient was positioned in the sitting position and after prep and drep, spinal anesthesia was performed at a L4-L5 level with a 25B-Braun needle and $15 \mathrm{mg}(3 \mathrm{ml})$ of $0.5 \%$ Bupivacaine. After the injection, patients were immediately aligned into a supine position.

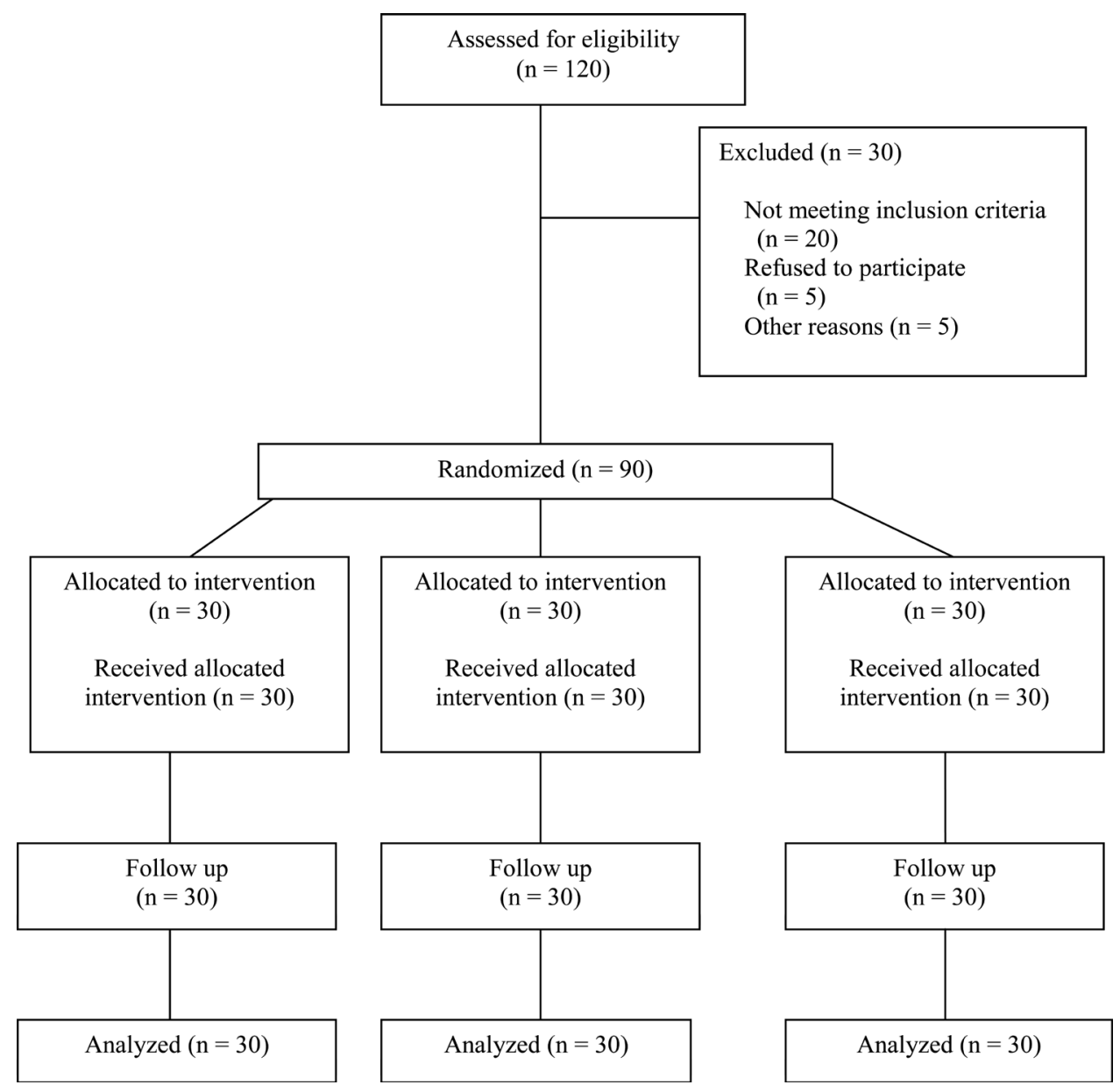

Figure 1. Flowchart of the study. 
To facilitate the double-blind method, all medications were prepared and injected by an anesthetist who was not involved in the study. Thus the patient and the observer were blinded to the groups. Following the preparation of intravenous line, $5 \mathrm{cc} / \mathrm{kg}$ lactated ringer's solution, store in the operating room, was infused through peripheral venous line and all patients received $1500 \mathrm{cc}$ lactated ringer's during surgery. The operating room temperature was maintained at $23^{\circ} \mathrm{C} \pm 1{ }^{\circ} \mathrm{C}$ and a standard blanket was used to cover all patients.

During surgery and $6 \mathrm{~h}$ thereafter, several factors including the presence or absence of shivering, and its severity based on a $1-4$ scale $(1=$ no shivering, $2=$ slight shivering in the muscles of head and neck, 3 = mild shivering in the head and neck and a limb, and $4=$ sever shivering in all parts of the body) were evaluated [14].

The time to reach the highest level of sensory block was considered as the onset block. Time of injection returning to a sensory block level to four dermatomes was considered as the duration of the sensory block. Total duration of analgesic was defined as the time from intrathecal injection to Pethidine injection.

After the end of the sensory block, the pain rate score was measured at each hour using the visual analogue scale (VAS) (zero means no pain and 10 is the most severe pain that a person has ever experienced). People with shivering more than grade 2 and a greater VAS or one that is equal to four were injected with $25 \mathrm{mg}$ of Pethidine [15] [16].

Blood pressure and heart rate were monitored during surgery and $6 \mathrm{~h}$ thereafter, and were recorded at baseline times of 5, 10, 15 and $30 \mathrm{~min}$. This was also completed at 1,2, 4 , and $6 \mathrm{~h}$ for the rest of the observation period. Decreased blood pressure, which was more than 30\% from basic blood pressure, or systolic blood pressure, which was less than $90 \mathrm{mmHg}$, was treated by 5 - $10 \mathrm{mg}$ of ephedrine, and bradycardia, defined as any rhythm disorder with a heart rate less than 60 , was treated with $0.5 \mathrm{mg}$ of atropine.

Side effects like nausea and vomiting during and post-operative were recorded by observing and questioning patients. To obtain 30\% reduction in expected incidence with $\alpha$ error of 0.05 and a $\beta$ error of 0.2 , a sample size of 30 patient per group was needed. Statistical analysis was completed using suitable statistical software, and a Student $t$-test and chi-square test were applied for the interpretation of the results. $P$-value of $<0.05$ was considered statistically significant.

\section{Results}

As noted previously, 90 patients were randomly divided into three groups of 30 patients whom were men in this study (Figure 1). The mean age of the patients was $33.06 \pm$ 12.56 years in the control group, $31.3 \pm 9.56$ years for patients in the Clonidine group, and $38 \pm 11.84$ years for patients in the Tramadol group, respectively.

The incidence of shivering in the study groups after spinal anesthesia is shown in Table 1.

The incidence of shivering was significantly lower in the control and Clonidine groups than that in the Tramadol group at $15 \min (P=0.007)$. However, the incidence of shivering was significantly lower in the Clonidine group than that in the control 
group at $30 \min (\mathrm{P}=0.020)$.

As Figure 2 shows, the severity of shivering in the Clonidine group at 15 and 30 min, and at 1, 2, and $4 \mathrm{~h}$ was significantly lower than that in the other two groups.

VAS score measurements are analyzed based on Kruskal-Wallis. VAS score measurements in the Clonidine group at 2 and $4 \mathrm{~h}$ were significantly lower than those in the other two groups $(\mathrm{P}=0.001)$, but there was no significant difference between the VAS

Table 1. The prevalence of shivering in study groups.

\begin{tabular}{cccc}
\hline Group Time & Control & Clonidine & Tramadol \\
\hline Base & 0 & 0 & 0 \\
5 minutes & 0 & 0 & 0 \\
15 minutes & 0 & 0 & 6 \\
30 minutes & 15 & 6 & 13 \\
1 hour & 16 & 8 & 8 \\
2 hours & 3 & 6 & 2 \\
4 hours & 0 & 0 & 0 \\
6 hours & 0 & 0 & 0
\end{tabular}

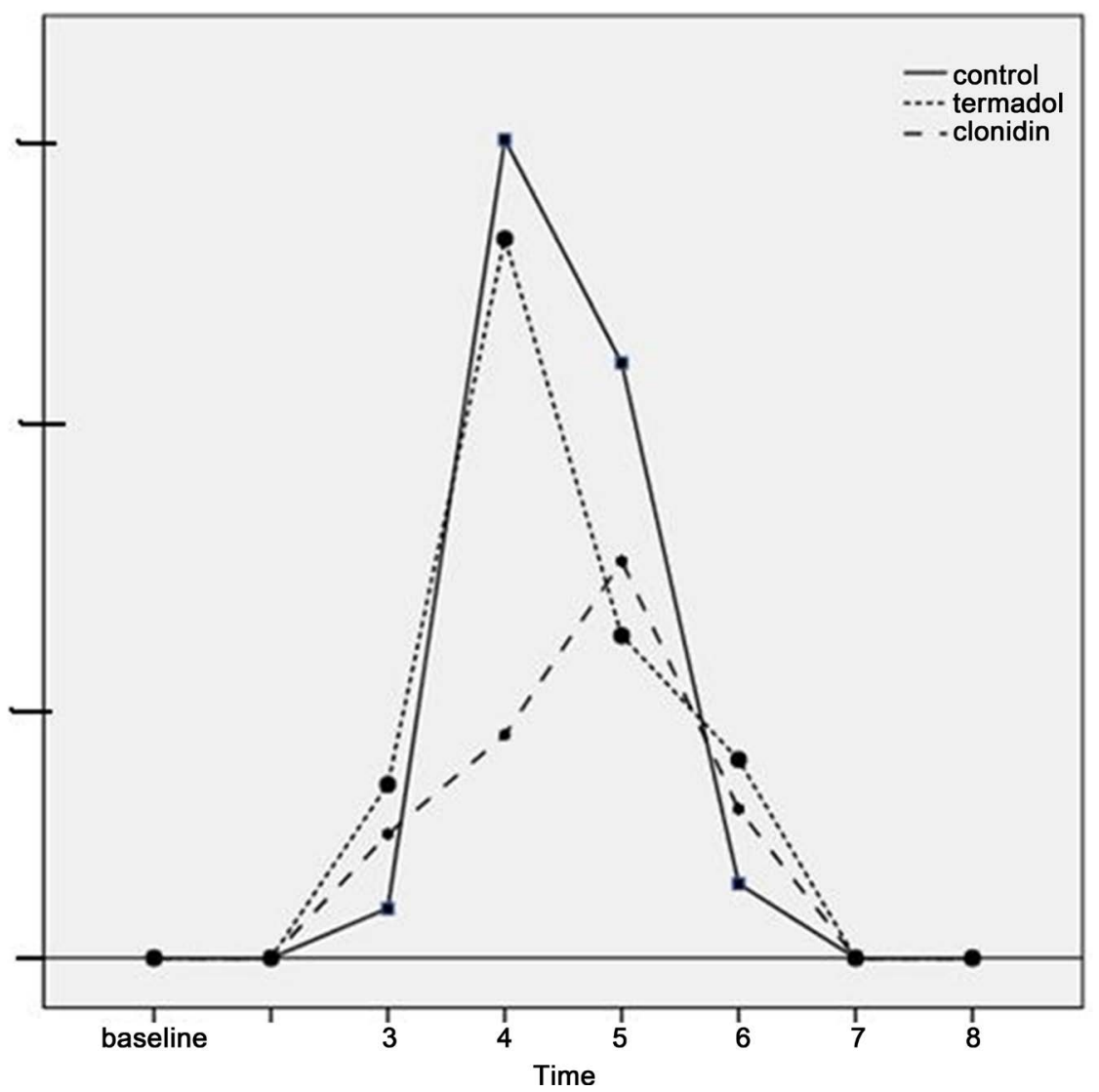

$1=$ base, $2=5$ minutes, $3=15$ minutes, $4=30$ minutes, $5=1$ hour, $6=2$ hours, $7=4$ hours, $8=6$ hours

Figure 2. The severity of shivering in the three groups of study. 
score measurements of the three groups' at $6 \mathrm{~h}(\mathrm{P}=0.189)$.

The mean duration of analgesia was $4 \mathrm{~h}$ and $15 \mathrm{~min}$ in the control group, $5 \mathrm{~h}$ in Clonidine group, and $4 \mathrm{~h}$ and $32 \mathrm{~min}$ in the Tramadol group, respectively. The duration of analgesia was significantly higher in the Clonidine group compared to the control group ( $\mathrm{P}=0.020)$, but there was no significant difference between both Clonidine and Tramadol groups $(\mathrm{P}=0.210)$ and also the Tramadol and control group $(\mathrm{P}=0.600)$. Mean Arterial Blood Pressure (MAP) in the three groups also showed no significant difference $(\mathrm{P}=0.069)$ (Table 2).

There was no significant difference with bradycardia regards to the change in blood pressure and between the three groups (Table 3). Nausea occurred in 6, 5, and 6 patients in the control, Clonidine, and Tramadol, respectively, and vomiting occurred in 3,5 , and 6 patients, respectively.

\section{Discussion}

The current study attempted to compare the effects of Clonidine and Tramadol in controlling postoperative shivering after spinal anesthesia. This study showed that Clonidine was more effective than Tramadol in preventing postoperative shivering. The duration of analgesia was significantly higher in the Clonidine group than the control group, but there was no significant difference between both the Clonidine and Tramadol groups.

In various studies, the prevalence of shivering in neuraxial blocks was suggested as $40 \%-70 \%$ [1] [2]. However, in this study, the incidence of shivering was $50 \%$ (in control group and at $30 \mathrm{~min}$ ). In a study by Wason et al. [12], the prevalence of shivering was $54 \%$ and was similar to that in the study of Sagir et al. [17]. Although, Sia et al. [18]

Table 2. Mean arterial blood pressure in the groups of study.

\begin{tabular}{ccccc}
\hline Group Time & Control & Clonidine & Tramadol & P-value \\
\hline Base & $90.60 \pm 11.13$ & $91.37 \pm 12.44$ & $92.13 \pm 7.71$ & 0.126 \\
5 minutes & $94 \pm 6.39$ & $90.93 \pm 6.64$ & $93.70 \pm 2.87$ & 0.690 \\
15 minutes & $87.57 \pm 12.64$ & $60.83 \pm 14.61$ & $79.80 \pm 14.71$ & 0.100 \\
30 minutes & $13.85 \pm 13.66$ & $93.83 \pm 11.09$ & $80.82 \pm 15.8$ & 0.723 \\
1 hour & $87.40 \pm 12.06$ & $53.84 \pm 6.42$ & $63.86 \pm 6.22$ & 0.419 \\
2 hours & $97.23 \pm 6.72$ & $30.85 \pm 5.40$ & $83.86 \pm 5.83$ & 0.425 \\
4 hours & $20.86 \pm 5.38$ & $50.84 \pm 22.8$ & $86.77 \pm 5.70$ & 0.383 \\
6 hours & $50.85 \pm 5.30$ & $33.85 \pm 5.51$ & $85.77 \pm 5.37$ & 0.952 \\
\hline
\end{tabular}

*Oneway ANOVA test.

Table 3. Complications in the groups of study.

\begin{tabular}{ccccc}
\hline Complications & Control & Clonidine & Tramadol & P-value \\
\hline Bradycardia & 10 & 8 & 9 & 0.530 \\
Hypotension & 9 & 7 & 10 & 0.685 \\
\hline
\end{tabular}


reported the incidence of shivering as less in their study (40\%), it was found in our study that the sensory block occurred with injections. Mepivacaine was 2\% (15- $20 \mathrm{ml}$ ) at T2, but in our study, it was given by injection. Bupivacaine was also 0.5\% [15 mg (3 $\mathrm{ml}$ )] at T4-T5, and this could be due to the difference in the incidence of shivering.

Hypothermia during central neuraxial block is common [1] and can be as severe as that seen during general anesthesia. Also, the rapid injection of cold intravenous fluids can be involved in creating shivering. Non-pharmacological methods using equipment such as covering with drapes (by blanket), using radiant heat and warming up operating rooms to maintain the normal temperature of the body are effective [19]. In this study, factors that influence the occurrence of shivering, such as the temperature of intravenous fluids, operating room, and medication temperature, are tightly controlled.

Clonidine is a centrally acting selective alpha $2(\alpha 2)$ agonist and is antihypertensive, sedative, analgesic, and anti-shivering, which binds to $\alpha 2$ Adrenoceptors causing vasoconstriction and anti-shivering. Additionally, clonidine has a thermoregulatory effect on the hypothalamus [20]. Clonidine is a centrally acting selective alpha 2 ( $\alpha 2)$ hypotensive agents, sedative, analgesic, and anti-shivering agonist. It exerts its anti-shivering effects at three levels: the hypothalamus, locus coeruleus, and spinal cord. At the hypothalamic level, it decreases the thermoregulatory threshold for vasoconstriction and shivering because the hypothalamus has a high density of $\alpha 2$ Adrenoceptors and is effective in treating the established post-anesthetic shivering [20].

The results of the present study are consistent with those of the study conducted by Mayo et al., which included 100 men over 40 years old with urologic surgery under spinal anesthesia in 1998 [21]. They found that the use of $15 \mathrm{mg}$ prophylactic oral Clonidine will be effective to prevent shivering after spinal anesthesia. The shivering rate was $4 \%$ in the study group and was $44 \%$ in the control group [21]. However, Tewari et al. found that $150 \mathrm{mg}$ of oral clonidine was effective to prevent shivering after a neuraxial block [20]. Dhorgiol et al. [22] also found that $150 \mathrm{mg}$ oral clonidine was effective in preventing shivering after a subarachnoid block. Furthermore, the results of our study corresponds to the findings by Vanderstappen et al. [23], who suggested that the incidence and severity of shivering in the study group was significantly lower than that in the control group.

Clonidine is known for inducing bradycardia and hypertension; however, in our study the incidence of bradycardia and hypertension in the Clonidine group was not significantly difference from that in the control group. In a study conducted by Javaherforoosh et al. [24], the outcomes of Clonidine, Pethidine, and Fentanyl were compared for the treatment of shivering. It was reported that hemodynamic conditions after treatment with Clonidine is better and more effective than Pethidine.

Tramadol is an opioid analgesic with opioid action preferably mediated more via the $\mu(\mathrm{mu})$ receptor and minimal via the $\mathrm{K}$ and sigma receptors. Tramadol also activates the monoaminergic receptors of the descending spinal cord (neuraxial) inhibiting pain pathway. This may also inhibit the uptake of adrenaline and serotonin at the synapse, which can help the analgesic effect [25]. Thus, Tramadol is effective in controlling 
post-spinal shivering [26]. Various studies have also shown that Tramadol can reduce the incidence, severity, and duration of postoperative shivering [27]-[29].

Bilotta et al. [30] and Chan et al. [31] Found that $0.5-0.25 \mathrm{mg} / \mathrm{kg}$ of intravenous Tramadol are effective in controlling shivering after neuraxial blocks. Gangopadhyay et al. [32] achieved useful results regarding that $1 \mathrm{mg} / \mathrm{kg}$ of intravenous Tramadol was effective in controlling post-spinal shivering.

However, Matthew et al. compared Tramadol and saline administration in shivering prevention and found that the incidence of shivering in the Tramadol group showed a significantly lower level than that in the control group [28]. De Witte et al. showed that high doses of Tramadol administration were effective in preventing postoperative shivering in all patients [1].

In our study, Tramadol did not affect the prevention of shivering. In the two above studies, Tramadol has been used intravenously, but in the present study, $50 \mathrm{mg}$ of oral Tramadol was used instead.

In a study conducted by Boxendol et al. [33] in which $1 \mathrm{mg} / \mathrm{kg}$ of Tramadol was used, there were no adverse effects, such as nausea and vomiting, which was similar to the present study. In addition, in multiple studies [27] [29] [34]-[36] Tramadol did not influence blood pressure and body temperature, and is consistent with the results of this study. Furthermore, the incidence of side effects was not significantly different among the groups. Tramadol increases the chance of nausea and vomiting, but in our study, the rate of nausea and vomiting in the Tramadol group has no significant difference when compared to the control group. Thus, previous studies had results similar to our results [4] [27]. Although, in the study of Gangopadhyay et al. [32], a significant number of patients (20 of 30 patients), who received Tramadol, suffered from nausea and vomiting. In this study, a dose of $1-\mathrm{mg} / \mathrm{kg}$ intravenous Tramadol was given, even though we used $50 \mathrm{mg}$ of oral Tramadol in our study (we used for Tramadol at oral dose levels up to $50 \mathrm{mg} / \mathrm{kg}$ ).

\section{Conclusion}

The result of this study demonstrated that orally administered Clonidine can be effective in preventing postoperative shivering after spinal anesthesia without complications. Limitation of this study was that the skin and core temperature during operating room period was not measured.

\section{Acknowledgements}

We thank the Clinical Research Development Unit of Rouhani Hospital.

\section{References}

[1] De Witte, J. and Sessler, D.I. (2002) Perioperative Shivering: Physiology and Pharmacology. Anesthesiology, 96, 467-484. http://dx.doi.org/10.1097/00000542-200202000-00036

[2] Sessler, D.I. and Ponte, J. (1990) Shivering during Epidural Anesthesia. Anesthesiology, 72, 816-821. http://dx.doi.org/10.1097/00000542-199005000-00008 
[3] Anders, H.W.B. (2002) Clinical Anesthesia Practice. 2nd Edition, Philadelphia.

[4] Bhatnagar, S., et al. (2001) Tramadol for Postoperative Shivering: A Double-Blind Comparison with Pethidine. Anaesthesia and Intensive Care, 29, 149-154.

[5] Katyal, S. and Tewari, A. (2002) Shivering: Anesthetic Considerations. Journal of Anaesthesiology Clinical Pharmacology, 18, 363-376.

[6] Daniel, S. (1994) Temperature Monitoring. In: Millar, R.D., Ed., Textbook of Anaesthesia. Churchill Livingstone, New York.

[7] Chan, A.M., Tong, E.W. and Jan, G.S. (2005) Textbook of Anesthesia. 6th Edition, Churchill Livingstone, USA.

[8] Eydi, M., et al. (2014) Postoperative Management of Shivering: A Comparison of Pethidine vs. Ketamine. Anesthesiology and Pain Medicine, 4, e15499. http://dx.doi.org/10.5812/aapm.15499

[9] Marashi, S.M., et al. (2014) Comparing Two Different Doses of Intravenous Ondansetron with Placebo on Attenuation of Spinal-Induced Hypotension and Shivering. Anesthesiology and Pain Medicine, 4, e12055. http://dx.doi.org/10.5812/aapm.12055

[10] Moghaddam, M.J., et al. (2013) Effects of Clonidine Premedication upon Postoperative Shivering and Recovery Time in Patients with and without Opium Addiction after Elective Leg Fracture Surgeries. Anesthesiology and Pain Medicine, 2, 107-110. http://dx.doi.org/10.5812/aapm.7143

[11] Alfonsi, P., et al. (2005) The Effect of Postoperative Skin-Surface Warming on Oxygen Consumption and the Shivering Threshold. Anaesthesia, 58, 1228-1234. http://dx.doi.org/10.1046/j.1365-2044.2003.03444.x

[12] Wason, R., et al. (2012) Randomized Double-Blind Comparison of Prophylactic Ketamine, Clonidine and Tramadol for the Control of Shivering under Neuraxial Anaesthesia. Indian Journal of Anaesthesia, 56, 370-375. http://dx.doi.org/10.4103/0019-5049.100821

[13] Imani, F., et al. (2013) Effects of Adding Ketamine to Fentanyl plus Acetaminophen on Postoperative Pain by Patient Controlled Analgesia in Abdominal Surgery. Anesthesiology and Pain Medicine, 4, e12162. http://dx.doi.org/10.5812/aapm.12162

[14] Wrench, I.J., et al. (1997) The Minimum Effective Doses of Pethidine and Doxapram in the Treatment of Post-Anaesthetic Shivering. Anaesthesia, 52, 32-36. http://dx.doi.org/10.1111/j.1365-2044.1997.006-az006.x

[15] Amri Maleh, P., et al. (2013) Effects of Gabapentin on Postoperative Pain Follow in Laparoscopic Cholecystectomy. Journal of Mazandaran University of Medical Sciences, 23, 2932. (Persian)

[16] Amri Maleh, P., et al. (2014) Comparison of Efficacy of Transdermal Fentanyl Patch and Intravenous Morphine on Postoperative Pain of Esophageal Cancer Surgery with TransHiatal Approach. Journal of Babol University of Medical Sciences, 16, 7-13. (Persian)

[17] Sagir, O., et al. (2007) Control of Shivering during Regional Anaesthesia: Prophylactic Ketamine and Granisetron. Acta Anaesthesiologica Scandinavica, 51, 44-49. http://dx.doi.org/10.1111/j.1399-6576.2006.01196.x

[18] Sia, S. (1998) I.V. Clonidine Prevents Post-Extradural Shivering. British Journal of Anaesthesia, 81, 145-146. http://dx.doi.org/10.1093/bja/81.2.145

[19] Nasiri, A., Akbari, A., Sharifzade, G. and Derakhshan, P. (2015) The Effects of Warmed Intravenous Fluids, Combined Warming (Warmed Intravenous Fluids with Humid-Warm Oxygen), and Pethidine on the Severity of Shivering in Generalanesthesia Patients in the Recovery Room. Iranian Journal of Nursing and Midwifery Research, 20, 712-716. http://dx.doi.org/10.4103/1735-9066.170014 
[20] Tewari, A., Dhawan, I., Mahendru, V., Katyal, S., Singh, A. and Narula, N. (2014) A Comparative Study Evaluating the Prophylactic Efficacy of Oral Clonidine and Tramadol for Perioperative Shivering in Geriatric Patients Undergoing Transurethral Resection of Prostate. Journal of Anaesthesiology Clinical Pharmacology, 30, 340-344. http://dx.doi.org/10.4103/0970-9185.137264

[21] Mao, C.C., Tsou, M.Y., Chia, Y.Y., Chow, L.H., Chan, K.H. and Lee, T.Y. (1998) PreAnesthetic Oral Clonidine Is Effective to Prevent Post-Spinal Shivering. Acta Anaesthesiologica Sinica, 36, 137-142.

[22] Dhorigol, M.G., Jain, N., Gupta, P. and Gogia, A.R. (2010) Randomized, Controlled Double Blind Study to Evaluate Oral Clonidine to Prevent Post-Subarachnoid Block Shivering in Patients Undergoing Elective Urological Surgery. Journal of Anaesthesiology Clinical Pharmacology, 26, 15-18.

[23] Vanderstappen, I., et al. (1996) The Effect of Prophylactic Clonidine on Postoperative Shivering. A Large Prospective Double-Blind Study. Anaesthesia, 51, 351-355. http://dx.doi.org/10.1111/j.1365-2044.1996.tb07747.x

[24] Aravind, V., Dhakshinamoorthy, M. and Dhanasekaran, C. (2014) A Comparative Study of Clonidine and Tramadol for the Control of Post Spinal Anaesthesia Shivering. International Journal of Modern Research and Reviews, 2, 379-384.

[25] Lee, C.R., McTavish, D. and Sorkin, E.M. (1993) Tramadol. A Preliminary Review of Its Pharmacodynamic and Pharmacokinetic Properties, and Therapeutic Potential in Acute and Chronic Pain States. Drugs, 46, 313-340. http://dx.doi.org/10.2165/00003495-199346020-00008

[26] Pausawasdi, S., Jirasirithum, S. and Phanarai, C. (1990) The Use of Tramadol Hydrochloride in the Treatment of Post-Anesthetic Shivering. Journal of the Medical Association of Thailand, 73, 16-20.

[27] Tsai, Y.C. and Chuks, A. (2001) A Comparison of Tramadol, Amitriptiline, and Meperidin for Post Epidural Anesthesia Shivering in Parturient. Anesthesia and Analgesia, 28, 12881292. http://dx.doi.org/10.1097/00000539-200111000-00052

[28] Mathews, S., Al Mulla, A., Varghese, P.K., Radim, K. and Mumtaz, S. (2002) Postanaesthetic Shivering-A New Look at Tramadol. Anaesthesia, 57, 394-398. http://dx.doi.org/10.1046/j.1365-2044.2002.2457 3.x

[29] Alfonsi, P. (2001) Postanaesthetic Shivering: Epidemiology, Pathophysiology, and Approaches to Prevention and Management. Drugs, 61, 2193-2205. http://dx.doi.org/10.2165/00003495-200161150-00004

[30] Bilotta, F., Pietropaoli, P., Sanita, R., Liberatori, G. and Rosa, G. (2002) Nefopam and Tramadol for Prevention of Shivering during Neuraxial Anesthesia. Regional Anesthesia and Pain Medicine, 7, 380-384.

[31] Chan, A.M., Ng, K.F.J., Nung Tong, E.W. and Jan, G.S.K. (1999) Control of Shivering under Regional Anesthesia in Obstetric Patients with Tramadol. Canadian Journal of Anaesthesia, 46, 253-258. http://dx.doi.org/10.1007/BF03012605

[32] Gangopadhyay, S., et al. (2010) Ketamine, Tramadol and Pethidine in Prophylaxis of Shivering during Spinal Anaesthesia. Anaesthesiology Clinical Pharmacology, 26, 59-63.

[33] Boxendol, B.R., Mahajon, R.P. and Crossly, A. (1994) Anticholinergic Premedication Influences the Incidence of Post Operative Shivering. British Journal of Anaesthesia, 72, 291294. http://dx.doi.org/10.1093/bja/72.3.291

[34] Kranke, P., Eberhart, L.H., Roewer, N. and Tramèr, M.R. (2002) Pharmacological Treatment of Postoperative Shivering: A Quantitative Systematic Review of Randomized Con- 
trolled Trials. Anesthesia and Analgesia, 94, 453-460.

[35] Reid, J.L. (1981) The Fourth Lilly Prize Lecture, University of Aberdeen, September 1980. The Clinical Pharmacology of Clonidine and Related Central Antihypertensive Agents. British Journal of Clinical Pharmacology, 12, 295-302.

http://dx.doi.org/10.1111/j.1365-2125.1981.tb01217.x

[36] Chow, T.C. and Cho, P.H. (1994) The Influence of Small Dose Intrathecal Fentanyl on Shivering during Transurethral Resection of Prostate under Spinal Anesthesia. Acta Anaesthesiologica Sinica, 32, 165-170.

\section{Submit or recommend next manuscript to SCIRP and we will provide best service} for you:

Accepting pre-submission inquiries through Email, Facebook, LinkedIn, Twitter, etc. A wide selection of journals (inclusive of 9 subjects, more than 200 journals)

Providing 24-hour high-quality service

User-friendly online submission system

Fair and swift peer-review system

Efficient typesetting and proofreading procedure

Display of the result of downloads and visits, as well as the number of cited articles Maximum dissemination of your research work

Submit your manuscript at: http://papersubmission.scirp.org/

Or contact ojanes@scirp.org 